\title{
Influence of Psychological Factors on the Ability to Diagnose Chronic Low Back Pain of Facet Joint Origin
}

\author{
Laxmaiah Manchikanti, MD*, Vidyasagar Pampati, MSc**, Bert Fellows, MA ${ }^{\Omega}$, Jose J. Rivera, MD\#, \\ Kim S. Damron, RN"\#, Carla Beyer, RN"\#, and Kim A. Cash, RT ${ }^{\Omega \Omega}$
}

This study was designed to determine the prevalence of lumbar facet joint pain in patients suffering with or without somatization disorder. The study was performed using comparative local anesthetic blocks.

One hundred consecutive patients with chronic low back pain, with or without somatization, were evaluated. The results showed that, among patients suffering with chronic low back pain, $44 \%$ of the patients without somatization and $38 \%$ of the patients with somatization were positive for facet joint pain. The diagnosis of facet joint pain was not influenced by the presence or absence of somatization disorder. The evaluation also was extended to depression, generalized anxiety disorder and combinations with or without

Facet joints have been implicated as responsible in $15 \%$ to $45 \%$ of patients with chronic low back pain in controlled studies utilizing a comparative local anesthetic double block paradigm (1-8). Thus, a preponderance of evidence supports the existence of lumbar facet joint pain (1-17). However, the concept of so-called lumbar facet syndrome has been questioned $(1,8,17)$. Diagnosis of facet syndrome depends on a clinical presentation, which is mainly dependent on the patient's symptomatology. It has also been shown that pain provocation is not a reliable sign in diagnosing lumbar facet joint pain $(9,18)$. The results of most studies have failed to show a correlation between imaging findings, clinical examination and controlled diagnostic blocks $(8,9,17)$. Carragee et al (19-22) created numerous questions and confusion about the value of provocation and diagnostic blocks, specifically in provocative discog-

From Pain Management Center of Paducah, Paducah, Kentucky. *Medical Director, **statistician, ${ }^{\Omega}$ psychologist,

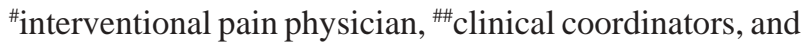

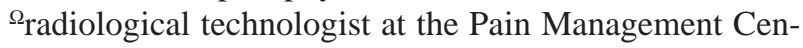
ter of Paducah. Address correspondence: Laxmaiah Manchikanti, MD, 2831 Lone Oak Road, Paducah, Kentucky 42003. E-mail: drm@ asipp.org somatization thereof which showed no significant differences in the prevalence of facet joint pain.

The results of this study demonstrated that the facet joint was a source of pain in chronic low back pain patients in $44 \%$ of the patients without somatization and $38 \%$ of the patients with somatization. This study also showed that there was no correlation between the presence or absence of facet joint pain and the presence or absence of somatization disorder or any other psychological condition or combination thereof.

Keywords: Chronic low back pain, facet joint pain, somatization disorder, depression, comparative local anesthetic blocks, false-positive response

raphy, in evaluating low back pain. Manchikanti et al (23) in an evaluation of patients with or without somatization concluded that provocative discography provided similar results in patients with or without somatization; with or without depression; with somatization but with or without depression; or with other combinations of the psychological triad of somatization disorder, depression, and generalized anxiety disorder. Many flaws of studies by Carragee et al (19-22) have been highlighted (23-25), including not only the evaluations being conducted in asymptomatic patients, but also the methodology's utilization in the evaluation of somatization and abnormal psychological features.

Factors such as depression, anxiety and excessive somatic perception are recognized as actively contributing to a patient's perception of pain (26-35). It is also well recognized that somatization disorder and depression are complex, psychological disorders. Somatization is an extremely common phenomenon, with approximately $60 \%$ to $80 \%$ being physically healthy people, including medical professionals, experiencing somatic symptoms in any given week (36). In addition, major depression, which is commonly seen in chronic low back pain (37-42), is also frequently reported in association with somatization (28, $30,32,37-40)$. The prevalence of somatization disorder and depression in chronic pain patients varies greatly, with 
somatization ranging from $0 \%$ to $97 \%(30,32-38,42)$ and depression ranging from $18 \%$ to $64 \%(37-42)$.

Somatization disorder may be accurately evaluated either using the Minnesota Multiphasic Personality Inventory (MMPI) or the Millon Clinical Multiaxial Inventory (MCMI). However, many authors have used the Modified Somatic Perception Questionnaire, as well as the Zung Self-Rating Depression Scales, for evaluation of somatization (43-45). Main (43) developed a Modified Somatic Perception Questionnaire (MSPQ) to measure increased bodily awareness. The MSPQ, which was specifically derived for use with chronic back pain patients, is a subjective test with a final 13-item scale which was developed from a pilot study of 102 chronic back pain patients. Main (43) assessed patients with back pain in an orthopedic outpatient clinic and concluded that they were clearly anxious and concerned about their pain. These patients described symptoms of increased sympathetic activity, which are closely allied to anxiety, but few met the criteria for anxiety neurosis; and they showed an understandable concern about their physical problem, but very few met the criteria for hypochondriasis. The common theme seemed to be increased bodily awareness rather than anxiety or hypochondriasis. They simply seemed to be more aware of their bodily symptoms and function. Even though the MSPQ is a 22-item questionnaire with a description ranging from not at all to could not have been worse at four levels, only 13 of these items are scored and added to give a total score. Deyo et al (46) reported a lack of correlation between the MSPQ and functional outcomes and only a weak association with pain outcomes. The Zung Self-Rating Depression scale is a specific test used for diagnosis of depression, even though some have attributed changes on these test scores to somatization. The constructive validity of the Zung Self-Rating Depression scale was questioned by Shotte et al (47). The MSPQ was compared with the Zung Depression Scale and the first three clinical scales of the MMPI (43). Thus, it is only appropriate to use the Zung Depression Scale for evaluation of depression and not for somatization. Similarly, the MSPQ is ideally used for measurement of bodily awareness rather than somatization. In contrast, with the MMPI or MCMI, it is not only somatization disorder which may be accurately evaluated; assessment of depression, anxiety and personality disorders is also achieved.

This study was undertaken to evaluate the influence of somatization, depression and generalized anxiety disorder on positive and negative responses to controlled, comparative local anesthetic blocks in the diagnosis of facet joint mediated pain in chronic low back pain.

\section{METHODS}

The study population consisted of 100 consecutive patients with a chief complaint of low back pain. Group I consisted of 50 patients without somatization (nonsomatization group), whereas Group II consisted of 50 patients with somatization disorder (somatization group). Patients younger than 18 years or older than 90 years, those who exhibited neurological deficits, those who had pain for less than 6 months, and those who presented with a definite diagnosis based on findings of radiologic or neurophysiologic testing were excluded.

All patients underwent psychological evaluation with MCMI-II, and the diagnosis of somatization disorder, depression and generalized anxiety disorder was established. Evaluation included completion of a standard questionnaire, history, and physical examination; and evaluation of the results of all procedures and investigations, in addition to psychological evaluation. The nature of the study and potential hazards of procedures were explained to all patients, all of whom provided informed choice and consent. Facet joints were investigated with diagnostic blocks using lidocaine $1 \%$ initially, followed by bupivacaine $0.25 \% 2$ to 4 weeks apart, unless the patient obtained relief longer than 4 weeks with the lidocaine block, in which case the blocks were repeated with bupivacaine upon return of the pain. The patients shown to be negative to facet joint nerve blocks underwent other evaluations and treatment.

The blocks were performed on the ipsilateral side in patients with unilateral pain, or bilaterally in patients with bilateral or axial pain. The blocks were mainly performed at L3 through L5; but various other levels up to L1 were included, when pain description and tenderness pointed to higher levels. The blocks were performed by one investigator in an operating room equipped with an imaging intensifier, with the patient in the prone position. Intravenous access and mild sedation with midazolam were carried out. Under intermittent fluoroscopy visualization, the blocks were performed at each of the medial branches at the L1 through L4 and L5 dorsal ramus, using a 22-gauge, 3.5-inch spinal needle. Each nerve was infiltrated with 0.4 to $0.6 \mathrm{~mL}$ of either $1 \%$ lidocaine or $0.25 \%$ bupivacaine. Following the blocks, patients were examined and previously painful movements were performed. A definite response was defined as substantial with at least $80 \%$ relief of pain in the symptomatic area following the local anes- 
thetic block, lasting at least 45 minutes with lidocaine and 2 hours with bupivacaine. The response to bupivacaine was judged positive only if it was longer than the response with lidocaine.

Data were recorded on a database using Microsoft ${ }^{\circledR}$ Access $^{\circledR}$. The SPSS Version 9.0 statistical package was used to generate the frequency tables, and the chi-squared statistic was used to test the significance difference between groups. Fisher's Exact Test was used wherever expected value was less than five. Student's t test was used to test mean difference between gender. Results were considered statistically significant if the $p$ value was less than 0.05 .

\section{RESULTS}

Data were evaluated for patient characteristics, psychological characteristics, and results of comparative local anesthetic blocks. The results were also correlated and compared not only with the nonsomatization and somatization groups, but also with patients with or without depression; with or without generalized anxiety disorder; with a combination of somatization with anxiety or depression; and, finally, with the presence or absence of all three conditions.

Table 1. Patient characteristics

\begin{tabular}{|c|c|c|c|}
\hline \multirow{2}{*}{\multicolumn{2}{|c|}{ Number of patients }} & $\begin{array}{c}\text { Group I } \\
\text { Nonsomatization }\end{array}$ & $\begin{array}{c}\text { Group II } \\
\text { Somatization }\end{array}$ \\
\hline & & $\mathrm{N}=50$ & $\mathrm{~N}=50$ \\
\hline \multirow{2}{*}{ Gender } & Male & $34 \%(17)$ & $40 \%(20)$ \\
\hline & Female & $66 \%(33)$ & $60 \%(30)$ \\
\hline \multirow{2}{*}{ Age (yrs.) } & Range & $22-83$ & $22-72$ \\
\hline & Mean + SEM & $53.1 *+2.48$ & $41.5+1.42$ \\
\hline \multirow{2}{*}{ Mode of onset of pain } & Following incident & $46 \%(13)$ & $58 \%(29)$ \\
\hline & Gradual onset & $54 \%(27)$ & $42 \%(21)$ \\
\hline \multirow{2}{*}{ Duration of pain (yrs) } & Range & $0.5-28$ & $0.5-28$ \\
\hline & Mean + SEM & $7.6+1.10$ & $6.5+0.79$ \\
\hline \multirow{2}{*}{ Pain distribution } & Unilateral & $18 \%(9)$ & $40 \%(20)$ \\
\hline & Bilateral & $82 \% *(41)$ & $60 \%(30)$ \\
\hline
\end{tabular}


Table 2. Number of patients with psychological abnormalities from both groups $(n=100)$

\begin{tabular}{lc}
\hline & Percent $(\mathrm{N}=100)$ \\
\cline { 2 - 2 } Any psychological condition & 78 \\
Generalized anxiety disorder & 60 \\
Depression & 44 \\
Somatization disorder and generalized anxiety disorder & 37 \\
Depression and generalized anxiety disorder & 37 \\
Somatization disorder and depression & 22 \\
Somatization disorder, depression and generalized anxiety disorder & 20 \\
\hline
\end{tabular}

$54 \%$, in Group II. Confirmatory blocks with bupivacaine were performed in 37 patients in Group I and 27 patients in Group II. Twenty-two patients, or $44 \%$ of the total sample in Group I, and nineteen, or $38 \%$ of the total sample in Group II, reported a definite response.

As shown in Table 3, all patients who withstood double blocks with definite response were considered as positive, with a prevalence rate of facet joint pain in chronic low back pain of $44 \%$ in Group I, and $38 \%$ in Group II. The false-positive rate with single blocks was $29 \%$ in Group I and $26 \%$ in Group II. There was no difference noted among groups with response to lidocaine block, bupivacaine, or false-positive rate with or without somatization.

Results of additional evaluation as shown in Table 4 included distribution of somatization disorder, depression, and generalized anxiety disorder by outcome of diagnostic facet joint nerve blocks. The diagnosis of facet joint pain was similar in patients suffering with depression, generalized anxiety disorder or various combinations of somatization disorder and depression; somatization disorder and generalized anxiety disorder; generalized anxiety disorder and depression; somatization disorder, generalized anxiety disorder and depression; any psychological condition or the absence of any psychological condition.

\section{Psychological Variables}

As shown in Table 5, generalized anxiety disorder correlated with depression $(p=0.000)$ and somatization disor$\operatorname{der}(p=0.008)$. There was no correlation between somatization disorder and depression.

\section{DISCUSSION}

Somatization disorder, depression and generalized anxiety disorder or combinations thereof are complex psychological issues. While the value of diagnosis of depression and generalized anxiety disorder is well accepted, the validity of somatization disorder is questioned (27). Aronoff et al (27) established that the diagnosis of somatization

Table 3. Comparison of the results of single blocks (lidocaine) and double blocks (lidocaine and bupivacaine)

\begin{tabular}{|c|c|c|c|c|}
\hline \multirow[b]{3}{*}{ Single blocks } & \multicolumn{2}{|c|}{ Group I } & \multicolumn{2}{|c|}{ Group II } \\
\hline & \multicolumn{2}{|c|}{ Double blocks } & \multicolumn{2}{|c|}{ Double blocks } \\
\hline & Positive & Negative & Positive & Negative \\
\hline Positive & 22 & 8 & 19 & 8 \\
\hline Negative & & 20 & & 23 \\
\hline Prevalence & \multicolumn{2}{|c|}{$44 \%$} & \multicolumn{2}{|c|}{$40 \%$} \\
\hline False-positive rate & \multicolumn{2}{|c|}{$29 \%$} & \multicolumn{2}{|c|}{$26 \%$} \\
\hline
\end{tabular}


Table 4. Distribution of somatization disorder, depression and generalized anxiety disorder by outcome of diagnostic blocks

\begin{tabular}{|c|c|c|}
\hline Somatization disorder & $\begin{array}{l}\text { Facet joint positive } \\
\qquad(\mathrm{N}=\mathbf{4 1})\end{array}$ & $\begin{array}{l}\text { Facet joint negative } \\
\qquad(\mathrm{N}=59)\end{array}$ \\
\hline Positive & $38 \%(19)$ & $62 \%(31)$ \\
\hline Negative & $44 \%(22)$ & $56 \%(28)$ \\
\hline \multicolumn{3}{|l|}{ Anxiety } \\
\hline Positive & $42 \%(25)$ & $58 \%(35)$ \\
\hline Negative & $40 \%(16)$ & $60 \%(24)$ \\
\hline \multicolumn{3}{|l|}{ Depression } \\
\hline Positive & $50 \%(22)$ & $50 \%(22)$ \\
\hline Negative & $34 \%(19)$ & $66 \%(37)$ \\
\hline Somatization disorder and generalized anxiety disorder & $35 \%(13)$ & $65 \%(24)$ \\
\hline Generalized anxiety disorder and depression & $46 \%(17)$ & $54 \%(20)$ \\
\hline Somatization disorder and depression & $41 \%(9)$ & $59 \%(13)$ \\
\hline $\begin{array}{l}\text { Somatization disorder, generalized anxiety disorder and } \\
\text { depression }\end{array}$ & $40 \%(8)$ & $60 \%(12)$ \\
\hline Any psychological condition & $45 \%(35)$ & $55 \%(43)$ \\
\hline No psychological condition & $27 \%(6)$ & $73 \%(16)$ \\
\hline
\end{tabular}

should meet the full criteria, including a history of having many physical complaints beginning before age 30, which have occurred over a period of several years and result in patients seeking treatment or significant impairment in social, occupational, or other important areas of functioning. In addition, the patient must also have four pain symptoms, two gastrointestinal symptoms, one sexual symptom, and one pseudoneurologic symptom. Further, a patient with somatization and pain disorder also should meet the criterion that after appropriate physical investigation, each of the previously named symptoms cannot be fully explained by a known general medical condition or by the direct effects of a substance; only then criteria for somatization disorder are considered to have been met (48). Further, in order to diagnose a patient with somatization disorder when there is a related general medical condition, the physical complaints or the social or occupational impairments that result from general medical conditions should be in excess of what would be expected from history, examination or laboratory findings $(27,48)$. All these criteria can only be satisfied by evaluation for somatization, either by using the MMPI, MCMI or another test which specifically evaluates for this condition rather than the MSPQ or Zung Depression Scale.

Major depression is a frequently reported condition in patients suffering with low back pain, either independently or in association with somatization and generalized anxiety disorder $(28,30,37,39-42,49-51)$. Thus, psychological problems are extremely common alone or in combination. Main and Waddell (51) noted that it is not our professional role to sit and pass judgment, but to understand the problem with compassion to provide the best possible management for each patient. They also summarized psychological distress in relation to chronic low back pain stating that, "Back pain arises from a physical problem in the back. It is usually not psychogenic. Back pain cannot be divided into physical or psychologic. Most patients with back pain are not personality deficient. They do not have a psychiatric disorder and they are not malingering."

The presence of psychological issues has been described as being akin to the diagnosis of chronic pain syndrome, which is a complex condition with physical, psychological, emotional, and social components $(52,53)$. It is well known that both chronic pain and chronic pain syndrome 
Table 5. Correlation among various psychological conditions

A. Correlation between depression and generalized anxiety disorder

\begin{tabular}{|c|c|c|c|}
\hline \multirow{4}{*}{ Generalized anxiety disorder } & & \multicolumn{2}{|c|}{ Depression } \\
\hline & & Positive & Negative \\
\hline & Positive & $37 \%$ & $7 \%$ \\
\hline & Negative & $23 \%$ & $33 \%$ \\
\hline \multicolumn{4}{|l|}{$\mathrm{P}=0.000$} \\
\hline \multicolumn{4}{|c|}{ B. Correlation between somatization disorder and generalized anxiety disorder } \\
\hline & & \multicolumn{2}{|c|}{ Somatization } \\
\hline & & Positive & Negative \\
\hline \multirow{2}{*}{ Generalized anxiety disorder } & Positive & $37 \%$ & $23 \%$ \\
\hline & Negative & $13 \%$ & $27 \%$ \\
\hline \multicolumn{4}{|l|}{$\mathrm{P}=0.008$} \\
\hline \multicolumn{4}{|c|}{ C. Correlation between depression and somatization disorder } \\
\hline & & \multicolumn{2}{|c|}{ Depression } \\
\hline & & Positive & Negative \\
\hline \multirow{2}{*}{ Somatization disorder } & Positive & $22 \%$ & $28 \%$ \\
\hline & Negative & $22 \%$ & $28 \%$ \\
\hline
\end{tabular}

are defined in terms of duration and persistence of the sensation of pain. However, chronic pain syndrome, as opposed to chronic pain, has the added component of certain recognizable, psychological and socioeconomic influences, with characteristic psychological and sociological behavior patterns inherent in chronic pain syndrome that distinguish the two conditions. Chronic pain syndrome, even though not an official nomenclature, is frequently used to describe the condition of an individual who is markedly impaired by chronic pain with substantial psychological overlay (53). It is also well known that chronic pain syndrome is largely a behavioral syndrome that affects a minority of those patients suffering with chronic pain. Thus, chronic pain may exist in the absence of chronic pain syndrome, but chronic pain syndrome always presumes the presence of chronic pain. The terminology recommended by the International Association for the Study of Pain has eliminated chronic pain syndrome from its glossary (54).

The literature shows that chronic pain syndrome is not a common phenomenon (55). Hendler and Kolodny (56) estimated that the incidence of psychogenic pain is only 1 in 3,000 patients. Hendler et al (57) also showed that organic origin of the pain is present in $98 \%$ of the cases after evaluating a number of cases which were referred to them as psychosomatic cases. Asmundson et al (58) showed that $17.8 \%$ of the patients with chronic musculoskeletal pain were diagnosed with a current anxiety disorder. Atkinson et al (59) in comparing patients with low back pain to a matched sample of pain-free men, found that chronic pain groups had significantly higher lifetime prevalence rates of major anxiety disorder, which was shown to be $30.9 \%$ in chronic low back pain patients versus $14.3 \%$ in pain-free patients. Others $(41,42,60)$ also showed an increased prevalence of anxiety disorders in patients suffering with chronic low back pain.

While it is quite apparent that psychological and/or emotional factors contribute significantly to determining how patients respond to the treatment, this does not necessarily mean that such patients are malingerers who are faking their level of disability or their suffering with psychogenic pain. Thus far, there is no convincing evidence that chronic low back pain develops secondary to psychopathology and that the response to treatment is hindered significantly 
based on psychopathology. The literature has shown that physical factors have been found to predict outcome in lumbar surgery (61). There has been a growing body of evidence indicating that psychosocial factors also may have significant influence on the outcome of lumbar surgery $(61,62)$. Results of research have shown that MMPI evaluations, especially with elevations on the hypochondriasis and hysteria subscales, can predict poor outcomes of back surgery (63-65). However, serious concerns have been presented about the psychometric soundness of the MMPI evaluation and its clinical utility for the specific population of patients with back pain $(61,66,67)$. In addition, the association between surgical outcome, depression, generalized anxiety disorder, somatization disorder, schizophrenia, and various personality disorders has not been explored.

Similarly, there is no such research available with nonsurgical interventional techniques. Most of the research has concentrated on a combination of multiple psychological factors, including personality disorders. Trief et al (61) utilizing the Spielberger Trait Anxiety Inventory, Zung Depression Scale, MSPQ, and Cook-Medley Hostility Scale, showed that failure to return to work was predicted by presurgical anxiety and depression; and failure to report improvement in pain and functional abilities was predicted by presurgical somatic anxiety and depression. They concluded that screening for presurgical distress is likely to identify those patients at risk for poor outcomes, and they recommended that presurgical psychological treatment and its relation to outcome should be studied. However, this is an extremely cumbersome evaluation prior to surgical interventions, and more so prior to nonsurgical interventional techniques.

Our results in two distinct groups of patients with or without somatization showed that there was no difference in our ability to diagnose facet joint pain with comparative local anesthetic blocks, in its prevalence, or false-positive rate of facet joint pain in chronic low back pain. In addition, we also evaluated patients with depression, generalized anxiety disorder and multiple combinations thereof without any influence on the ability to diagnose facet joint pain in chronic low back pain patients. There were only a small number of patients presenting with the complex triad of somatization disorder, depression, and generalized anxiety disorder. We also assessed correlation between various conditions, including depression and generalized disorder, depression and somatization disorder, somatization disorder and generalized anxiety disorder. This study showed that there was no correlation noted between de- pression and somatization. However, there was significant correlation between somatization disorder and generalized anxiety disorder and between generalized anxiety disorder and depression.

The current study is the first prospective trial using comparative local anesthetic blocks to evaluate patients with chronic low back pain for the presence of facet joint pain in two distinct groups of patients, namely with or without somatization disorder. The results of this study show that, while psychological symptoms are present in conjunction with low back pain, these do not result in either positive or false-positive facet joint nerve blocks. Hence, these patients should not be refused care due to the results of psychological evaluation, as many of these patients concurrently suffer legitimate physical problems, namely facet joint pain in this case, which may improve following appropriate management of physical conditions.

\section{CONCLUSION}

This study shows that comparative local anesthetic facet joint nerve blocks yield similar results, irrespective of the patient's psychological condition; the presence or absence of somatization disorder, depression; and multiple other combinations of somatization disorder, depression, and generalized anxiety disorder. In addition, this study shows significant correlation between somatization disorder and generalized anxiety disorder, and depression and generalized anxiety disorder; whereas there is no correlation between somatization disorder and depression in this group of patients. Hence, the association of psychological conditions with a physical condition is a common phenomenon in patients suffering with chronic low back pain.

\section{REFERENCES}

1. Manchikanti L, Singh V, Kloth D et al. Interventional techniques in the management of chronic pain: Part 2.0. Pain Physician 2001; 4:24-96.

2. Manchikanti L, Singh V, Pampati V et al. Evaluation of the relative contributions of various structures in chronic low back pain. Pain Physician 2001; 4: in press.

3. Schwarzer AC, Aprill CN, Derby R et al. Clinical features of patients with pain stemming from the lumbar zygapophysial joints. Is the lumbar facet syndrome a clinical entity? Spine 1994; 19:1132-1137.

4. Schwarzer AC, Wang S, Bogduk N et al. Prevalence and clinical features of lumbar zygapophysial joint pain: A study in an Australian population with chronic low back pain. Am Rheum Dis 1995; 54:100-106. 
5. Schwarzer AC, Aprill CN, Derby R et al. The relative contributions of the disc and zygapophyseal joint in chronic low back pain. Spine 1994; 19:801-806.

6. Manchikanti L, Pampati VS, Fellows B et al. Prevalence of lumbar facet joint pain in chronic low back pain. Pain Physician 1999; 2:59-64.

7. Manchikanti L, Pampati VS, Bakhit CE et al. The diagnostic validity and therapeutic value of lumbar facet joint nerve blocks with or without adjuvant agents. Cur Rev Pain 2000; 4:337-344.

8. Manchikanti L, Pampati V, Fellows B et al. The inability of the clinical picture to characterize pain from facet joints. Pain Physician 2000; 3:158-166.

9. Bogduk N. International Spinal Injection Society guidelines for the performance of spinal injection procedures. Part 1: Zygapophyseal joint blocks. Clin J Pain 1997; 13:285-302.

10. Manchikanti L. Facet joint pain and the role of neural blockade in its management. Cur Rev Pain 1999; 3:348-358.

11. Hirsch D, Inglemark B, Miller M. The anatomical basis for low back pain. Acta Orthop Scand 1963; 33:1.

12. Kuslich SD, Ulstrom CL, Michael CJ. The tissue origin of low back pain and sciatica: A report of pain response to tissue stimulation during operation on the lumbar spine using local anesthesia. Orthop Clin North Am 1991; 22:181-187.

13. Mooney V, Robertson J. The facet syndrome. Clin Orthop 1976; 115:149-156.

14. McCall IW, Park WM, O'Brien JP. Induced pain referral from posterior elements in normal subjects. Spine 1979; 4:441-446.

15. Marks R. Distribution of pain provoked from lumbar facet joints and related structures during diagnostic spinal infiltration. Pain 1989; 39:37-40.

16. Schwarzer AC, Wang S, Laurent $\mathrm{R}$ et al. The role of the zygapophysial joint in chronic low back pain. Aust N Z J Med 1992; 22:185.

17. Schwarzer AC, Derby R, Aprill CN et al. Pain from the lumbar zygapophysial joints: A test of two models. J Spinal Disord 1994; 7:331-336.

18. Schwarzer AC, Derby R, Aprill CN et al. The value of the provocation response in lumbar zygapophysial joint injections. Clin J Pain 1994; 10:309-313.

19. Carragee EJ. Is lumbar discography a determinate of discogenic low back pain: Provocative discography reconsidered. Curr Rev Pain 2000; 4:301-308.

20. Carragee EJ, Chen Y, Tanner CM et al. Provocative discography in patients after limited lumbar discectomy. A randomized study of pain response in symptomatic and asymptomatic subjects. Spine 2000; 25:30653071.

21. Carragee EJ, Tanner CM, Khurana $\mathrm{S}$ et al. The rates of false-positive lumbar discography in select patients without low back symptoms. Spine 2000; 25:13731381.
22. Carragee EJ, Paragioudakis SJ, Khurana S. 2000 Volvo award winner in clinical studies. Lumbar high-intensity zone and discography in subjects without low back problems. Spine 2000; 25:2987-2992.

23. Manchikanti L, Singh V, Pampati V et al. Provocative discography in low back pain patients with or without somatization disorder: A randomized prospective evaluation. Pain Physician 2001; 4:227-239.

24. Wetzel FT. Rates of false-positive lumbar discography: Point of view. Spine 2000; 25:1381.

25. Tsou PM. Letter to the editor. Spine 2001; 26:994995.

26. Tollison CD, Satterthwaite JR. Chronic benign pain: Diagnosis and behavioral management. J Musculoskeletal Med 1991; 8:55-66.

27. Aronoff GM, Tota-Faucette M, Phillips L et al. Are pain disorder and somatization disorder valid diagnostic entities. Curr Rev Pain 2000; 4:309-312.

28. Lipowski ZJ. Somatization and depression. Psychosomatics $1990 ; 31: 13-21$.

29. Sullivan M, Katon W. Somatization: The path between distress and somatic symptoms. Am Pain Soc J 1993; 2:141-149.

30. Fishbain DA. Somatization, secondary gain, and chronic pain: Is there a relationship? Curr Rev Pain 1998; 6:101-108.

31. American Geriatrics Society. The management of chronic pain in older persons: New guidelines from the American Geriatrics Society. J Am Geriatr Soc 1998; 46:128-150.

32. Katon W, Kleinman A, Rosen G. Depression and somatization a review. Part I. Am J Med 1982, 72:127135 .

33. Sikorski JM, Stampfer HG, Cole RM et al. Psychological aspects of chronic low back pain. Aust N Z J Surg 1996; 66:294-297.

34. Bacon NM, Bacon SF, Atkinson JH et al. Somatization symptoms in chronic low back pain patients. Psychosom Med 1994; 56:118-127.

35. Korbon GA, DeGood DE, Schroeder ME et al. The development of a somatic amplication rating scale for low back pain. Spine 1987; 12:787-791.

36. Kellner R, Sheffield BR. The one-week prevalence of symptoms in neurotic patients and normals. Am J Psychiatry 1973; 130:102-105.

37. Rush AJ, Polatin P, Gatchel RJ. Depression and chronic low back pain. Spine 2000; 25:2566-2571.

38. Cassisi JE, Sypert GW, Lagara L et al. Pain disability and psychosocial function in CLBP subgroups: Myofascial versus herniated disc. Neurosurgery 1993; 33:379-385.

39. Magni G, Caldieron C, Rigatti-Luchini S et al. Chronic musculoskeletal pain and depressive symptoms in the general population: An analysis of the $1^{\text {st }}$ National Health and Nutrition Examination Survey data. Pain 1990; 43:299-307. 
40. Von Korff M, Simon G. The relationship between pain and depression. Br J Psychiatry 1996; 30:101108.

41. Fishbain DA, Cutler R, Rosomoff HL et al. Chronic pain associated depression: Antecedent or consequence of chronic pain? A review. Clin J Pain 1997; 13:116137.

42. Manchikanti L, Pampati V, Fellows B et al. Characteristics of chronic low back pain in patients in an interventional pain management setting: A prospective evaluation. Pain Physician 2001; 4:131-142.

43. Main CJ. The modified somatic perception questionnaire. J Psychosom Res 1983; 27:503-514.

44. Carragee EJ, Kim D. A prospective analysis of MRI findings in patients with sciatica and lumbar disc herniation: Correlation of outcomes with disk fragment and canal morphology. Spine 1997; 22:1650-1660.

45. Main C, Wood P, Hollis S et al. The distress and risk assessment method (DRAM): A simple patient classification to identify distress and evaluate the risk of a poor outcome. Spine 1992; 17:42-52.

46. Deyo RA, Walsh NE, Schoenfeld LS et al. Studies of the modified somatic perceptions questionnaire (MSPQ) in patients with back pain. Psychometric and predictive properties. Spine 1989; 14:507-510.

47. Schotte CK, Maes M, Cluydts R et al. Effects of affective-semantic mode of item presentation in balanced self-report scales: Biased construct validity of the Zung Self-rating Depression Scale. Psychol Med 1996; 6:1161-1168.

48. Diagnostic and Statistical Manual of Mental Disorders, Fourth Edition, American Psychiatric Association, Washington, 1993.

49. Dworkin RH, Gitlin MJ. Clinical aspects of depression in chronic pain patients. Clin J Pain 1991; 7:7994.

50. Banks SM, Kerns RD. Explaining high rates of depression in chronic pain: A diathesis-stress framework. Psychol Bull 1996; 119:95-110.

51. Main CJ, Waddell G. Psychologic distress. In Waddell (ed). The Back Pain Revolution, Churchill Livingstone, New York, 1998, pp 173-186.

52. Rucker KS. Chronic Pain Evaluation. Butterworth/ Heinemann, Boston 2001.

53. Coccharella L, Andersson GBJ (eds). Pain. Guides to the Evaluation of Permanent Impairment, Fifth Edition American Medical Association, Chicago, 2000, pp 565-591.
54. Merskey H, Bogduk N. Classification of chronic pain Descriptions of Chronic Pain Syndromes and Definitions of Pain Terms, Second edition. IASP Press, Seattle, 1994.

55. Corran TM, Farrell MJ, Helme RD et al. The classification of patients with chronic pain: Age as a contributing factor. Clin J Pain 1997; 13:207-214.

56. Hendler NH, Kolodny AL. Using medication wisely in chronic pain. Patient Care 1992; May 15:125.

57. Hendler NH, Bergson C, Morrison C. Overlooked physical diagnoses in chronic pain patients involved in litigation. Part 2. Psychosomatics 1996; 37:509-517. 58. Asmundson GJ, Jacobson SJ, Allerdings MD et al. Social phobia in disabled workers with chronic musculoskeletal pain. Behav Res Ther 1996; 34:939-943.

59. Atkinson JH, Slater MA, Patterson TL et al. Prevalence, onset, and risk of psychiatric disorders in men with chronic low back pain: A controlled study. Pain 1991; 45:111-121.

60. McCracken LM, Gross RT, Aikens J et al. The assessment of anxiety and fear in persons with chronic pain: A comparison of instruments. Beh Res Ther 1996; 34:927-933.

61. Trief PM, Grant W, Fredrickson B. A prospective study of psychological predictors of lumbar surgery outcome. Spine 2000; 25:2616-2621.

62. Block AR. Pre-surgical Psychological Screening in Chronic Pain Syndromes. Lawrence Erlbaum Associates, Mahwah, 1996.

63. Riley JL, Robinson ME, Geisser ME et al. Relationship between MMPI-2 cluster profiles and surgical outcome in low-back pain patients. J Spinal Disord 1995; 8:213-219.

64. Spengler DM, Ouelette EA, Battie M et al. Elective discectomy for herniation of a lumbar disc. J Bone Joint Surg 1990; 12:230-237.

65. Herron CD, Turner J, Clancy $\mathrm{S}$ et al. The differential utility of the MMPI: A predictor of outcome in lumbar laminectomy for disc herniation vs. spinal stenosis. Spine 1986; 11:847-850.

66. Chapman SL, Pemberton JS. Prediction of treatment outcome from clinically derived MMPI clusters in rehabilitation for chronic low back pain. Clin J Pain 1994; 10:267-276.

67. Turk DC, Fernandez E. Personality assessment and the Minnesota Multiphasic Personality Inventory in chronic pain: Underdeveloped and overexposed. Pain Forum 1995; 4:104-107. 